\title{
BY THE PEOPLE, FOR THE PEOPLE: THE CROWDSOURCING OF "STREETBUMP", AN AUTOMATIC POTHOLE MAPPING APP
}

\author{
F. Carrera ${ }^{\mathrm{a},}$, S. Guerin ${ }^{\mathrm{b}, \mathrm{c}}$, J. B. Thorp ${ }^{\mathrm{b}, \mathrm{d}}$
}

\author{
${ }^{\text {a }}$ Worcester Polytechnic Institute, City Lab, Interdisciplinary and Global Studies Division, 100 \\ Institute Road, Worcester, MA 01609, USA - carrera@wpi.edu \\ ${ }^{\mathrm{b}}$ Santa Fe Complex, Santa Fe, New Mexico \\ ${ }^{c}$ Redfish Group, Santa Fe, New Mexico - stephen@redfish.com \\ ${ }^{\mathrm{d}}$ Stigmergic Productions, Santa Fe, New Mexico - josh@stigmergic.net
}

KEY WORDS: Mobile Application, Road Conditions, Urban Maintenance, Crowdsourcing, Pothole Mapping

\begin{abstract}
:
This paper traces the genesis and development of StreetBump, a smartphone application to map the location of potholes in Boston, Massachusetts. StreetBump belongs to a special category of "subliminal" crowdsourcing mobile applications that turn humans into sensors. Once started, it automatically collects road condition information without any human intervention, using the accelerometers and GPS inside smartphones.

The StreetBump app evolved from a hardware device designed and built by WPI's City Lab starting in 2003, which was originally intended to measure and map boat wakes in the city of Venice, Italy (Chiu, 2004). A second version of the custom hardware with onboard GPS and accelerometers was adapted to use in Boston, Massachusetts, to map road damage (potholes) in 2006 (Angelini, 2006).

In 2009, Prof. Carrera proposed to the newly created office of New Urban Mechanics in the City of Boston to migrate the concept to Smartphones, based on the Android platform. The first prototype of the mobile app, called StreetBump, was released in 2010 by the authors (Harmon, 2010). In 2011, the app provided the basis for a worldwide Innocentive competition to develop the best postprocessing algorithms to identify the real potholes vs. other phone bumps (Moskowitz, 2011). Starting in 2012, the City of Boston has begun using a subsequent version of the app to operationally manage road repairs based on the data collected by StreetBump.

The novelty of this app is not purely technological, but lies also in the top-to-bottom crowdsourcing of all its components. The app was designed to rely on the crowd to confirm the presence of damage though repeat hits (or lack thereof) as more users travel the same roads over time. Moreover, the non-trivial post-processing of the StreetBump data was itself the subject of a crowdsourced competition through an Innocentive challenge for the best algorithm. The release of the StreetBump code as open-source allowed the development of the final version of the app now used on a daily basis by the Department of Public Works in Boston, thus making it perhaps the first example of an app that was crowdsourced "from soup to nuts".
\end{abstract}

\section{INTRODUCTION}

It has been estimated that potholes cost the average American driver almost $\$ 400$ a year in automobile repairs. The total repair expenses attributable to road damage amounted to $\$ 67$ billion in 2008, in the U.S. alone (U.S. PIRG, 2010). If we extrapolate these figures to the entire world, it is clear that road maintenance is a significant problem of global magnitude.

Road damage is an inevitable consequence of our increasing dependence on automobiles and trucks to move people and goods in and out of cities around the globe. The maintenance of roads is a necessity that local governments face on a daily basis. It is a never-ending battle that drains the meagre maintenance budgets of municipalities and it is a battle that many towns are losing. The American Society of Civil Engineers issues a yearly scorecard for U.S. infrastructure and many U.S. Cities and Towns are failing miserably. The overall grade in 2013 is a measly D+ (ASCE, 2013).

As is the case for dental cavities, repairing a pothole when it first begins to appear on the asphalt is a lot cheaper than letting it rot away until the damage is more extensive. In fact, the old saying "an ounce of prevention is worth a pound of cure" (a ratio of 1:16) is almost precisely what is suggested in the following infographic (Fig. 1), courtesy of the National Center for Pavement Preservation at Michigan State University
(AASHTO, 2009), which shows how one dollar of prevention saves $\$ 14$ later (a ratio of 1:14).

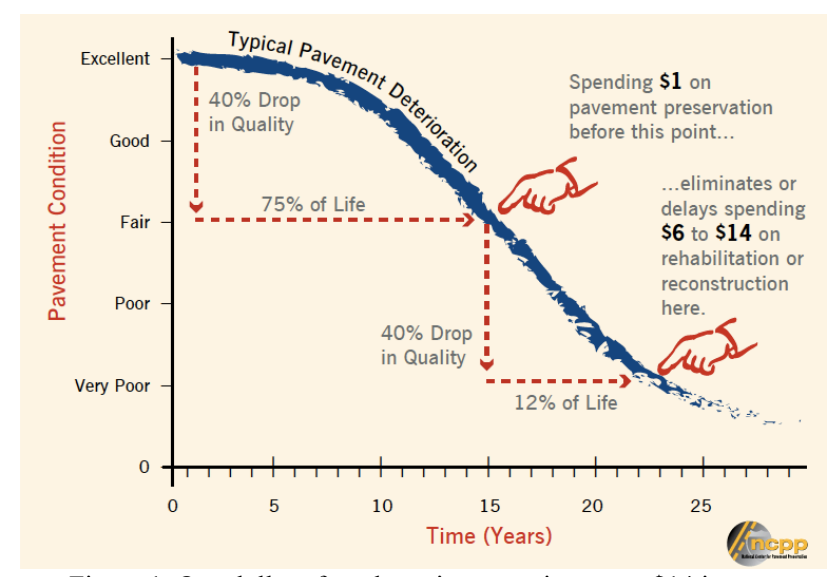

Figure 1. One dollar of road repair prevention saves $\$ 14$ in cure (source NCPP via AASHTO, 2009).

The project presented herein addresses the need to prioritize the "ounce" of preventive repairs to defer the expensive "pound of cure" as long as possible. With our StreetBump app, citizens 
and staffers can map the conditions of a city's roads automatically and "subliminally", essentially voting for street repairs with their cars' suspensions, every time they hit a pothole.

\section{HISTORY OF THE PROJECT}

StreetBump has a decade-long history and curiously traces its origins to a hardware device designed to map the turbulence created in Venice's inner canals by speeding motorboats. This custom water-born instrument, later evolved into a hardware device to map potholes on land, which finally morphed into the much friendlier and ubiquitous StreetBump app for Android.

\subsection{Venice's Turbulence Mapper}

StreetBump's grandfather was a device developed to map and measure the damaging effects of motorboat wakes (Moto ondoso) on the stone buildings along Venice's canals (Chiu, 2002).

The pioneering Wake Turbulence Mapping device (Chiu, 2004) included a microprocessor, LED indicators, a GPS receiver, accelerometers and a flash card inside a waterproof enclosure (Figure 2).



Figure 2. The original Venice Turbulence Mapper

(Chiu, 2004).

The prototype tested well in the canals of Venice (Fig. 3) and the technology was soon transplanted from the Venice Project Center to the Boston Project Center, where it was adapted to measure potholes instead of wakes.

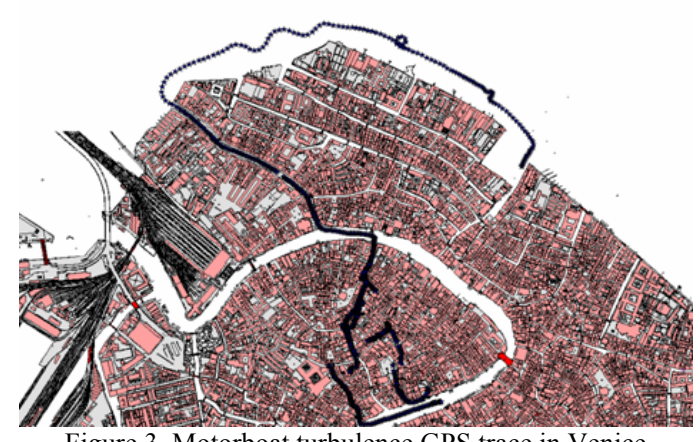

Figure 3. Motorboat turbulence GPS trace in Venice (Chiu, 2004).

\subsection{Boston's Pothole Mapper}

The original Pothole Mapper (Angelini, 2006) was designed and built to automatically detect road bumps and record their locations using GPS (Fig. 4), much like its Venice predecessor did. Being land-based and stationary (unlike the ephemeral wakes of Venice), the potholes' locations were stored according to their geographic coordinates, using "space as an index", as suggested by the principles of City Knowledge - a municipal information infrastructure approach developed at MIT (Carrera, 2004).

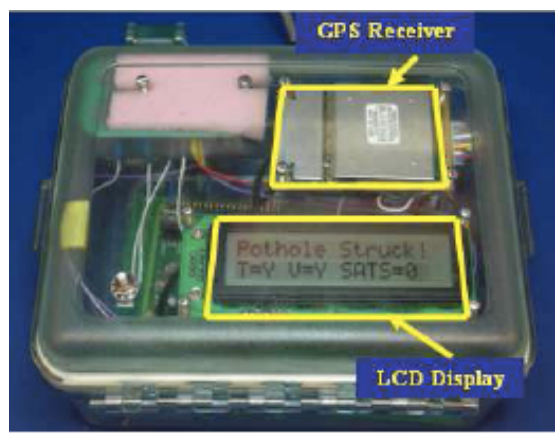

Figure 4. The original Pothole Mapper (Angelini, 2006).

This custom-built hardware device was intended to be utilized in municipal vehicles that already roam the city's streets as they provide routine municipal services like police patrols, garbage collection, street sweeping, plowing, etc.. The device would unobtrusively collect the pothole data and several of these devices would, over time, produce a map containing clouds of dots around pothole locations, with the intensity of the bump providing a measure of the pothole's severity (Fig. 5).

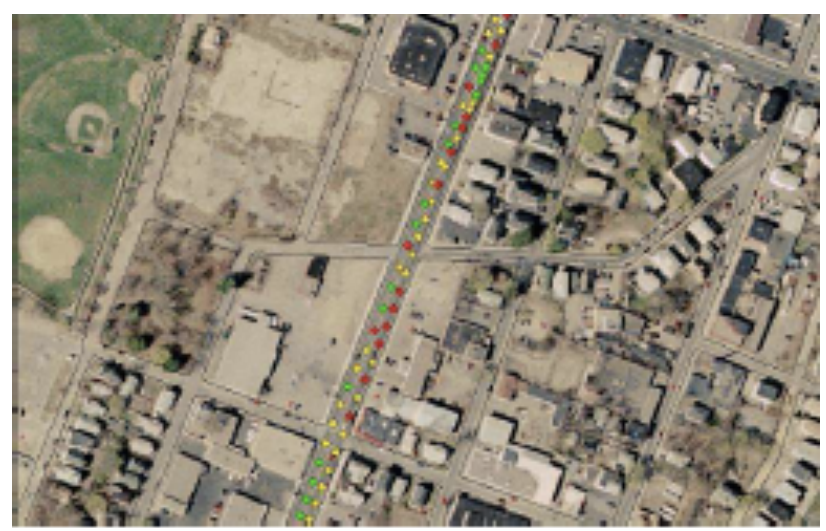

Figure 5. Automatically geo-located pothole clouds colored by severity (Angelini, 2006).

Mayor Menino of Boston expressed serious interest for the device, so much so that plans were made to install our prototype in the "Mayoral SUV" in the spring of $2006^{*}$. Meanwhile, as WPI's City Lab explored a patent application for the device, MIT researchers extended our idea to assess road conditions using additional sensors (Eriksson, 2008).

\subsection{Mapping potholes with Smartphones}

Having already produced the hardware Pothole Mapper, when smartphones began incorporating accelerometers and GPS, Prof. Carrera immediately proposed to the City of Boston the creation of a next-generation mobile app to map potholes using Android phones and no additional hardware (Carrera, 2009). Exactly one year later the project was announced in the Boston Globe (Harmon, 2010).

\footnotetext{
* Unfortunately, an unforeseen emergency forced the Mayor to cancel the planned installation at the last minute and the device went back to the lab.
} 


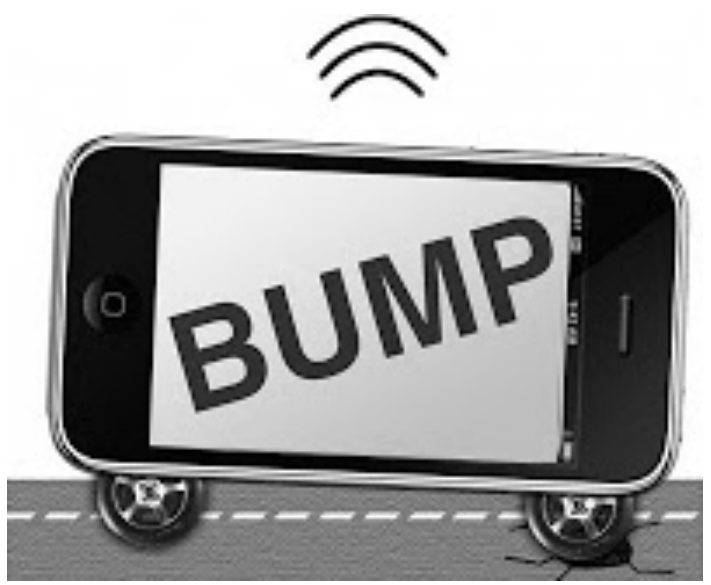

Figure 6. BUMP graphic in the original Boston Globe article (Harmon, 2010)

Mayor Menino's office of New Urban Mechanics supported the development of an operational prototype that established the feasibility of the project. The app was originally called BUMP (Boston Urban Mechanics Profiler) in honour of the funding office (Fig. 6), but had soon to be renamed Street Bump*.

\section{STREETBUMP}

The StreetBump app (Fig. 7) was co-designed by the three authors and programmed (in Processing) primarily by Josh Thorp exclusively for the Android platform, despite the iPhone being shown in the Boston Globe article (see Fig. 6).

In essence, what the StreetBump app does is to record the GPS locations wherever the phone's accelerometers detect a significant "bump" and save the data to a remote server (StreetBump, 2013), where each "track" is viewable both as a Map as well as a sparkline type of graphic (Tufte, 2006).

Android was a natural choice since an open-source philosophy and a spirit of crowdsourcing permeated the entire evolution of the project, from its origins as a student research project in Venice in 2003, to its operational adoption by the City of Boston in 2012 (ironically as an iPhone app only).



Figure 7. The main StreetBump screen (v. 1.3).

From beginning to end, the StreetBump project was a collaborative effort meant to cost little or nothing to develop and maintain, and intended to be used by citizens and city workers as a day-to-day, useful tool to map street anomalies in real time, thus making road repairs more timely, hence drastically reducing the costs to both the city and the citizens.

\footnotetext{
* We had to rename the app since there was already an app called Bump, so we called it Street Bump.
}

\subsection{The StreetBump app}

Frequent incremental versions of the StreetBump app (Fig. 8) were released on the Android app store from March 2010 until

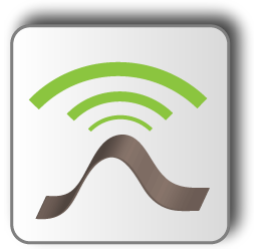

Figure 8. The Android StreetBump app icon. July 2011, culminating with version 1.3 , which is still available on the Google Play store, under "Street Bump (alpha)", and still publishes the bump maps and sparkline graphs (on line at apps.citizapps.com. The official announcement of the working prototype of StreetBump in 2011 (Moskowitz, 2011) generated significant buzz in major international websites (like Popular Science), as well as in very prestigious international technology blogs, such as Wired, Slashdot, Engadget and Techmeme, even getting picked up by Il Sole 24 Ore, the equivalent to the Wall Street journal in Italy and many others (Carrera, 2011).

\subsection{Humans as Sensors via "Subliminal" Crowdsourcing}

Despite all the attention that StreetBump continues to receive, no journalist thus far seems to have really caught on to the real innovation it represents. Everyone has been mesmerized by the "coolness" of the concept behind the mobile app, but few have stopped to reflect on the real novelty here, which is not purely technological, but lies primarily in the very special form of crowdsourcing employed by the app. In fact, the City of Boston already had an app, called Citizen Connect, that allows the crowd to report the presence of potholes. The problem of that form of self-reporting is that it relies on motivated users. Once the novelty of the app has worn off, it is hard to imagine a tool like Citizen Connect being used by a multitude of civic-minded citizens on a daily basis. There is simply too much competition for attention in the world of apps to expect that a user would: (a) know about the existence of the app, (b) have it installed, (c) remember about it when he/she sees a pothole and (d) run it right there and then to report the pothole.

StreetBump employs a different approach that removes items (c) and (d) from the above list of obstacles, though it still needs to deal with issues (a) and (b), like all other apps have to.

StreetBump effectively turns humans into sensors, by removing any conscious act on the part of the user, other than simply starting up the app and letting it run in the background of the smartphone, while driving to/from work or anywhere else within the City. After being intentionally or automatically turned on, StreetBump records any major bump experienced by the phone and maps its location on a server (Fig. 9).
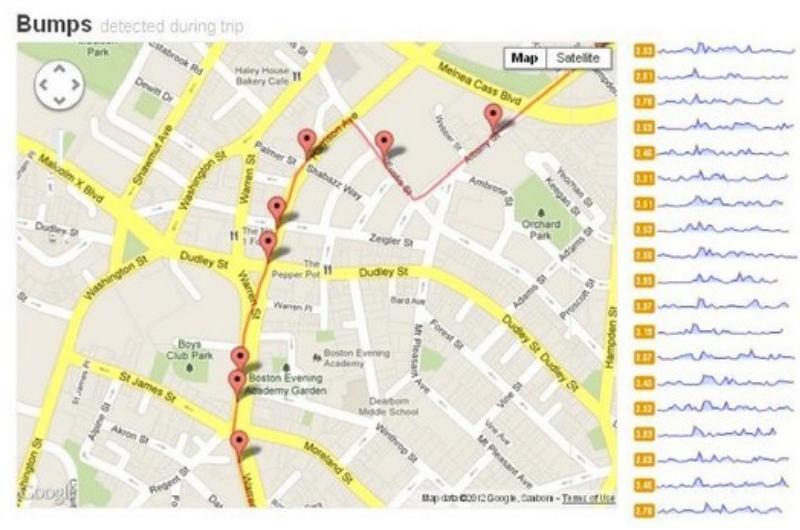

Figure 9. StreetBump map and sparklines. 
To bypass obstacles (a) and (b), StreetBump - like the original hardware Pothole Mapper - was intended all along to be used primarily by city staffers operating City vehicles, relying on citizen input only as a form of "voting" to prioritize repairs.

Much like Google's page-rank algorithm indexes internet searches based on the collective choices we express as we "intentionally surf" the web, StreetBump employs a form of "subliminal" crowdsourcing, in the sense that the user does not have to consciously decide to report a pothole, as Citizen Connect expects one to do.

Instead, we purposely designed StreetBump to be a two-step process that would separate the data collection on the mobile device from the data analysis on the server. As it turned out, both aspects employed crowdsourcing to arrive at a solution, as explained in the two sections that follow.

\subsection{Crowdsourcing the Data Collection}

StreetBump's major departure from all prior pothole mapping systems published in the literature (c.f. Eriksson, 2008) is that StreetBump does not attempt to validate the presence of an actual pothole while the car is moving over it. Instead, in StreetBump, each bump is recorded by the phone's accelerometers at a specific GPS location whenever the hit exceeds a set threshold. In and of itself, an individual hit at a specific location, generated from a certain phone on some trip across town does not necessarily imply the presence of a pothole. A false-positive bump could simply be caused by answering a phone call and shaking the accelerometers up and down in the process.

StreetBump simply records the potential for a pothole as a "bump" and leaves it to the wisdom of crowds to resolve whether a hit is a real pothole, based on repeat confirmations by other drivers, who are highly unlikely to be all answering the phone at the same location.

StreetBump purposely does not care about confirming the pothole on the fly, since we could statistically (or perhaps



\section{STREET} BUMP bayesianly) rely on the crowd

to provide the necessary forensics to confirm the pothole's presence through repeat hits (or lack thereof), with a certain signature, as several app users traveled the same road in short succession.

\subsection{Crowdsourcing the Data Analysis}

The purposeful separation of the mobile data collection from the ex-post identification of real potholes on the server, made it possible to consider engaging the crowds in the post-processing as well, using yet another crowdsourcing approach, pioneered by Boston-based Innocentive corporation (Innocentive, 2011a). Through Innocentive, the office of New Urban Mechanics challenged over 250,000 scientists all over the world to come up with the best algorithm to successfully identify real potholes from our Street Bump data (Innocentive, 2011b).

The $\$ 25,000$ contest, which was financed by Boston-based Liberty Mutual Insurance, attracted over 700 solvers and produced 19 submissions, out of which three winners were announced in July 2012 (Innocentive, 2012). On the same day, the City also released the iPhone version of the app (Fig. 10), packaged, by Connected Bits (the same company that produces Citizen Connect). The Apple version of our app has now become the de-facto "official" StreetBump app for the City of Boston.

Despite the fact that it cannot record bumps in the background, the iPhone app created by Connected Bits has been used extensively in Boston since its debut in the summer of 2012, albeit primarily by City staffers, as opposed to citizens at large. Based on an IP-sharing agreement between the authors and the City of Boston, the Connected Bits app inherited all of our source code as well as all of the winning algorithms from the Innocentive challenge. All of the code for our Android version of StreetBump is still available as open-source as should also be the code for the Apple version for iPhone.

\section{CONCLUSIONS AND FUTURE WORK}

With the advent of smartphones, the StreetBump app was the logical next step in the decade-long evolution of our Pothole Mapper so it made sense that Mayor Menino of Boston would support its development, given its pedigree.

Among other things, the development of StreetBump proves that innovation is indeed possible in the public sector, and great tools can be produced inexpensively and then broadly shared. All of these qualities bode well for future municipal apps based on City Knowledge principles (Carrera, 2004).

Since we were the original inventors and developers of StreetBump and we acted as judges in the Innocentive challenge, we never had a chance to produce our own StreetBump 2.0 version. If we were given the opportunity, we would produce the next generation of StreetBump using HTML5, as we are doing on a project for UNESCO (Carrera, 2012a), so that the app could work on any device capable of running a browser.

Our approach to the identification of potholes would entail endowing each street bump with its own intelligence, using the latest City Knowledge techniques (Carrera, 2012b) and use complexity-based approaches pioneered in Santa Fe to identify probable potholes (Fig. 11).

口



Figure 11. Complexity-based ant algorithms and pothole agents would explore nearly co-located "bumps" to confirm the presence of a pothole and estimate its severity.

Each time the smartphone's accelerometers detect a bump, StreetBump 2.0 would stigmergically spawn an ant-like "intelligent urban agent" at that GPS location. Nearby bump agents would find each other in close proximity and inspect each other's accelerometer signatures to strengthen or weaken their respective Bayesian beliefs about being a pothole or not. 
The busy ants would gradually learn how to separate the wheat from the chaff to produce a reliable map of potholes with very high confidence. To remove any further doubt, our pothole agents would also be able to enlist the assistance of humans to confirm their own beliefs, by sending out alerts to subscribing mobile apps.

In the end, we plan to embed StreetBump 2.0 inside an allencompassing Mobile City Knowledge platform that is capable of collecting and publishing a plethora of municipal data, and allows a variety of city processes to subscribe to sensor data in multiple devices, as well as to engage citizens as human sensors to crowdsource the collection of timely urban data on a need-to basis, with proper rewards and incentives, minimal interruption and maximum privacy and security for contributing citizen scientists.

In addition to being a "cool idea", StreetBump epitomizes the open approach to crowdsourced software development, since every aspect of its creation has been produced by the people, for the people.

StreetBump may soon be coming full-circle back to its Venetian origins, since the gondoliers' guild has expressed interest in a version of the app to document the moto ondoso that affects the iconic row boats of Venice. The project will have thus returned to its ancestral roots, after a decade-long evolution from a bulky hardware device into a sleek smartphone app that empowers citizens across the globe to effortlessly contribute to the upkeep of their home city.

\section{REFERENCES}

American Association of State Highways and Transportation Officials (AASHTO), (2009). Rough Roads. http://roughroads.transportation.org/, last accessed: March 19, 2013.

American Society of Civil Engineers (ASCE), (2013). 2013 Report Card for America's Infrastructure. http://www.asce.org/reportcard/, last accessed: March 19, 2013

Angelini, N., Brache, J., Gdula, M., Shevlin, C., 2006. GPS Coordinated Pothole Mapping. WPI Major Qualifying Project.

Carrera, F., (2012b). The City Knoweldge Platform: a Demonstration of Agent-oriented Programming for Intelligent City Maintenance, Management and Modeling. Workshop on Intelligent Agents in Urban Simulations and Smart Cities at the European Conference on Artificial Intelligence (ECAI 2012).

Montpellier, France: August 28, 2012.

Carrera, F., (2012a). Crowdsourcing (and Crowdfunding) the Preservation of Venice's Material Culture, Annual Meeting of the American Institute for Conservation of Historic and Artistic Works (AIC), Albuquerque, NM: May 8-11, 2012.

Carrera, F., (2011). "Street Bumps", blog post at http://venice2point0.blogspot.com/2011/03/street-bumps.html, March 20, 2011.

Carrera, F., (2010). "Bump!", blog post at http://venice2point0.blogspot.com/2010/03/bump.html, March 4, 2010.

Carrera, F., (2009). "The ide(a)s of March", blog post at http://venice2point0.blogspot.com/2009/03/ideas-ofmarch.html, March 15, 2009.
Carrera, F., (2004). City Knowledge: An emergent information infrastructure for sustainable urban maintenance, management and planning, Doctoral Dissertation, Massachusetts Institute of Technology, Cambridge, MA.

Chiu, D., Lacasse, C., Menard, K., (2004). Mapping Turbulent Motorboat Discharges in the Canals of Venice, Italy. WPI Major Qualifying Project.

Chiu, D., Jagganath, A., Nodine, E., (2002). The Moto Ondoso Index: Assessing the Effects of Boat Traffic in the Canals of Venice. WPI Interactive Qualifying Project.

Eriksson, J., Girod, L., Hull, B., Newton, R., Madden, S., Balakrishnan, H., (2008). The Pothole Patrol: Using a Mobile Sensor Network for Road Surface Monitoring. Mobisys'08. Brackenridge, CO.

Harmon, L., The Boston Globe (2010). Boston - We have an app for that. March 2, 2010. http://www.boston.com/bostonglobe/editorial_opinion/oped/arti cles/2010/03/02/boston__we_have_an_app_for_that/

Innocentive, (2012). Innocentive and Boston Mayor Thomas M. Menino Announce Winners in Challenge to Convert Big Data into Pothole Relief. Blog post at: http://www.innocentive.com/innocentive-and-boston-mayorthomas-m-menino-announce-winners-challenge-convert-bigdata-pothole-rel. July 20, 2012. Last accessed: March 15, 2013.

Innocentive, (2011b). Mayor Menino Launches Contest to Enhance Smartphone App that Detects and Reports Potholes. Blog post at: http://www.innocentive.com/mayor-meninolaunches-contest-enhance-smart-phone-app-detects-and-reportspotholes. May 4, 2011. Last accessed: March 15, 2013.

Innocentive, (2011a). City Releases Prototype of Smart Phone App that Detects Potholes. Blog post at: http://www.innocentive.com/city-releases-prototype-smartphone-app-detects-potholes. February 9, 2011. Last accessed: March 15, 2013.

Moskowitz, E., The Boston Globe. (2011). Weapons in the Battle Against Potholes. February 9, 2011. http://www.boston.com/news/local/massachusetts/articles/2011/ 02/09/weapons_in_the_battle_vs_potholes/.

Stedman, C., DeMarco, A., (2007). Automatic GPS Mapping of Road Roughness. WPI Major Qualifying Project.

StreetBump original web site, (2013). http://apps.citizapps.com/apps/bump/ . Last accessed: March 17, 2013.

Tufte, E. R., (2006). "Beautiful Evidence," Sparklines: Intense Word-Sized Graphics, Graphic Press LLC, Cheshire, CT., pp. 46-63.

U.S. PIRG, (2010). Road Work Ahead. http://www.uspirg.org/reports/usp/road-work-ahead. April 28, 2010.

\section{ACKNOWLEDGMENTS}

The authors would like to thank Mayor Menino of Boston and the "mechanics" of the Mayor's Office of New Urban Mechanics: Chris Osgood and Nigel Jacob for funding the research, design and development of StreetBump. 